\title{
Dutch translation and adaptation of the Barkley Deficits in Executive Functioning Scale (BDEFS)
}

\author{
Judith C. L. M. BeERTen-Dujukers1,2 \\ htps://orcid org/0000-0002-2742-4167
}

\author{
CONSTANCE TH. W. M. VISSERS 3 ,4
}

MiKe RinCK ${ }^{4}$

Russell A. Barkley5*

https://orcid.org/0000-0002-8185-3800

Jos I. M. EGGER $1,2,6,7^{*}$

https://orcid.org/0000-0002-9311-9013

'Donders Institute for Brain, Cognition and Behaviour, Radboud University Nijmegen, The Netherlands.

${ }^{2}$ Centre of Excellence for Korsakoff and Alcohol Related Cognitive Dysfunctions

Addiction Care, Vincent van Gogh Institute for Psychiatry, Venray, The Netherlands.

${ }_{3}^{3}$ Kentalis Academy, Royal Dutch Kentalis, Sint-Michielsgestel, The Netherlands.

${ }^{4}$ Behavioural Science Institute, Radboud University Nijmegen, The Netherlands.

${ }^{5}$ Department of Psychiatry, Virginia Commonwealth University Medical Center, Richmond, Virginia, USA.

${ }^{6}$ Centre of Excellence for Neuropsychiatry, Vincent van Gogh Institute for Psychiatry, Venray, The Netherlands.

7 Stevig Specialized and Forensic Care for People with Intellectual Disabilities, Dichterbij, Oostrum, The Netherlands.

*Prof. Barkley and Prof. Egger contributed equally and shared senior authorship.

Received: 8/21/2018- Accepted: 5/21/2019

DOl: 10.1590/0101-60830000000202

\begin{abstract}
Background: Based on his model of self-regulation and executive functions, Barkley developed a self- and other-report questionnaire (the Barkley Deficits in Executive Functioning Scale - BDEFS). The BDEFS measures deficits in executive functions as expressed in daily life activities like self-management of time, self-organization, self-restraint, self-motivation, and self-regulation of emotion. Objectives: This study created and analyzed a Dutch translation and adaptation in conformance with official guidelines. Methods: The Dutch and English BDEFS were completed by 25 bilingual Dutch adults to evaluate semantic correspondence. Consequently, 60 Dutch participants completed the Dutch BDEFS, Barratt Impulsiveness Scale-Eleventh edition (BIS-11) and the Dysexecutive Questionnaire (DEX) to evaluate concurrent validity and internal consistency. Results: The versions demonstrated sufficient semantic equivalence and Spearman's rho of total scores was high; items mostly showed moderate-to-high correlations. Regression analysis showed no proportional bias. Internal consistency was also high. Correlations between BDEFS, BIS-11 and DEX supported concurrent validity. Discussion: We conclude that a successful BDEFS translation and adaptation was created with satisfactory reliability and validity. Further research should assess the utility of the BDEFS in Dutch clinical practice.
\end{abstract}

Beerten-Duijkers JCLM et al. / Arch Clin Psychiatry. 2019;46(4):89-96

Keywords: Self-regulation, executive functions, assessment, reliability, validity.

\section{Introduction}

Executive function is currently seen as being compromised in several mental disorders (for example ${ }^{1-10}$ ). Barkley ${ }^{11}$ defined executive function as "self-regulation across time for the attainment of one's goals (self-interests), often in the context of others"11. Self-directed executive actions, such as self-speech, self-imagery, and selfmotivation, are seen as needed to self-regulate oneself throughout daily life situations. All executive behavioral actions interact by adulthood and are necessary to some extent to achieve adequate selfregulation in daily life. Moreover, these executive actions directed to the self can help to change behavior flexibly in situations in which automatic tendencies would lead to inadequate behavior.

Barkley divides the model of self-regulation into two levels: an automatic level and an executive level that monitors and injects several (executive) actions into the automatic level. This can be outlined as follows. When a situation is encountered in daily life (stage 1 automatic level), one pays more or less attention to the situation (stage 2 automatic level), one appraises it in a certain way (stage 3 automatic level) after which one responds by behavior (stage 4 automatic level). The course of attention (stage 2 ) towards appraisal and responses (stages 3 and 4) is influenced and controlled by all the executive level actions as mentioned in the model. That is, the appraisal of situations is executively influenced by both self-awareness (for example: signaling/consciously recognizing that one already has been in a situation like currently happening), inhibition (for example: suppression of an impulsive response tendency), working memory (for example: one may think back to earlier dysfunctional responses and update aspects of the current situation in order to show other response), regulation of one's own emotions (preventing to getting overwhelmed and managing to come to a healthy appraisal and response) and planning and problem solving executive actions, in order to come to a suitable self-regulatory response and handling of the current situation. The appraisal of a situation logically also influences executive functions like emotion regulation: When one appraises a situation as a risky one as a consequence of earlier traumatic experiences, one may feel anxiety mounting, which in turn influences the need for an executive emotion regulation action. As self-regulatory executive function is compromised in several mental disorders, its assessment is relevant for diagnostics and tailor made treatment indications.

Barkley earlier criticized the frequent practice of assessing executive functioning by neurocognitive tasks solely, without measurements by means of self-rating scales. Neuropsychological 
ability tasks and self-rating measures show high contrasts in correlational analyses ${ }^{12}$. Furthermore, he argued that several studies showed that rating scales have higher ecological validity in predicting impairment in various major life activities than do technical tests ${ }^{13-15}$. That is, several neuropsychological EF tests can have a pitfall in the creation of an "artificial" clinical lab situation that insufficiently touches real life. In contrast, insight into daily life executive functioning asks for more direct, real life, "natural" observations of human behavior as well, or self-/other-ratings of one's actions. This criticism of classical neuropsychological tests is partly illustrated by authors like Lezak ${ }^{16}$ who describes that a large amount of neuropsychological tests show insufficient reliability scores, and Barkley and co-authors revealed low predictive validity scores for those tests ${ }^{17,18}$. Patients with, for example, disorders like ADHD and frontal lobe disorders, frequently show average scores on those classical tests, although their disorders are distinctly associated with several self-regulatory problems in daily life situations that point to executive functioning impairments ${ }^{13}$. Furthermore, Barkley refers to several studies that show traditional ability tests to correlate low with scores on self-rating instruments touching executive functioning ${ }^{13}$. Elaborating on this, neuropsychological research seems to crave and search for the integrative use (and thereby option for comparisons) of both more technical, ideally ecologically valid ability tests and selfreport measures. Using only one of these instead of a combination of both may create a blind spot for other perspectives.

In line with his stated vision that favors the use of self-rating scales, Barkley presented the Barkley Deficits in Executive Functioning Scale (BDEFS) as a questionnaire in a self-rating and other-rating form ${ }^{19}$. He intended the BDEFS to be used in clinical practice, to measure aspects of executive deficits. It is based on his theoretical model of executive functioning and self-regulation as stated above (Figure 1). For the operationalization, he translated parts of the self-directed executive actions as described (selfawareness, inhibition, working memory, emotion regulation, and plan/problem solving) into measurable scales with the following names: self-management to time (linked to working memory, such as self-speech and self-imagery), self-organization (linked to plan/ problem solving), self-restraint (linked to inhibition), self-motivation (linked to various executive actions) and self-regulation of emotion (linked to behavioral inhibition and working memory).

Compared to other highly cited theoretical models of executive functioning (for example ${ }^{20}$ ), Barkley's model and BDEFS questionnaire distinctly accentuate both "cold", technical/cognitive, and more emotional or "hot" components of executive functioning.

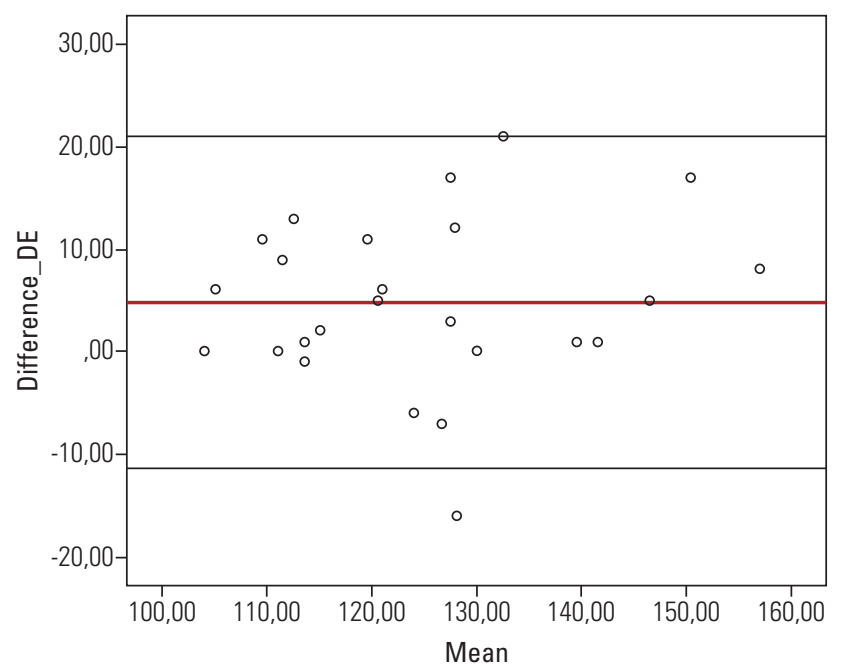

Figure 1. Bland Altman plot.

Difference_DE: Difference in Dutch and English BDEFS total scores; mean: mean total score Dutch and English versions.
Concerning "cold" aspects one can think of planning, problem solving and self-management of time (for example: getting things technically fixed/done on time). "Hot" components involve self-motivation and emotion regulation (for example, being able to inhibit strong emotions and calm oneself once a person has become emotional in a complex situation that evoked stress). Barkley developed both an adult and a child BDEFS version (to be filled in by caregivers) ${ }^{19,21}$.

As Barkley's model of self-regulation integrates both neurocognitive and emotional perspectives, and leads to the development of the BDEFS questionnaire, this study will provide a Dutch translation and adaptation of the BDEFS. It will also evaluate its psychometric properties so as to form a basis for its use in future clinical practice studies within the Dutch speaking community. The results are therefore expected to eventually have implications for tailored psychological assessment and may allude to new treatment options. During the translation and adaptation process of the BDEFS, international guidelines as provided by the ISPOR were adhered to ${ }^{22}$. Furthermore, an earlier successful Brazilian-Portuguese transcultural adaptation served as an example ${ }^{23}$.

The main question addressed here is if the Dutch translation and adaptation process of the BDEFS, conforming as it did to international guidelines, was successful. In that case, does the translation have sufficient evidence of reliability and validity. Our first hypothesis was if the BDEFS original and Dutch versions showed sufficient semantic equivalence. In other words, do the definitions and practical meanings of all corresponding questionnaire items in both versions have sufficient similarity. The second hypothesis concerned the Dutch BDEFS translation specifically and focused on whether or not it showed sufficient internal consistency and reliability (Cronbach's alpha). The third hypothesis dealt with the concurrent validity of the Dutch BDEFS translation by comparing it with the DEX and BIS11, which are two questionnaires that measure the concepts of executive dysfunctions and impulsivity, respectively.

\section{Methods}

\section{Participants}

Two samples of participants were recruited in successive phases in the translation and adaptation process. For the comparison phase of the English and Dutch BDEFS versions, participants had to be bilingual, which was accompanied by a higher level of education in this participant group. For the Dutch BDEFS version analyses, a broader range of educational levels was sought, yielding a more representative reflection of the general population. Recruitment took place via (local) social media platforms. To participate, interested individuals had to have at least an eighth grade education, be a native speaker of Dutch, and have normal or corrected-to-normal visual and reading abilities, and place between ages 18 to 81 . Participants that reported having had neurological disease or damage, head trauma with loss of consciousness for more than 10 minutes, and/or a current medical condition significantly impairing neurocognitive functions, were excluded. After the initial translation phase, 25 bilingual Dutch adults filled in both the original English language BDEFS and the Dutch version. The mean age in this group was 36.24 years (range 2551 years), 16 women and 9 men participated, and educational history ranged from five years of higher secondary education to a university degree. For the pilot study phase that intended to assess psychometric properties and concurrent validity, 60 Dutch individuals participated, with a mean age of 42.72 years (range $22-72$ years). In this group, 33 women and 27 men participated, and educational history ranged from four years of lower secondary education to a university degree.

\section{Materials}

* Barkley Deficits in Executive Functioning Scale (BDEFS), original English version and Dutch translation. The BDEFS is an 89-item questionnaire, using a four-point Likert-scale response style: never or seldom, sometimes, often, and very often. As mentioned, it aims 
to measure one's experience of problems concerning self-directed executive actions. Scales that were derived from factor analysis are: self-management to time (items 1-21), self-organization (and problem-solving; items 22-45), self-restraint (inhibition; items 4664), self-motivation (items 65-76), and self-regulation of emotion (items 77-89). The questionnaire consists of both a self-rating form and an other-rating form. Furthermore, a short version is available that consists of 20 items, derived from the long 89 -item version. For the present study the self-rating, long form is used. However, the other-rating questionnaire has also been translated based on the self-rating translation, because it basically consists of the same items; the only difference is that it contains "He/she" sentences instead of "I" sentences. The 89-item questionnaire takes 15 to 20 minutes to complete, and it is suitable for assessment with adults from 18 to 81 years. Various lines of evidence in addition to factor analysis as set forth in the manual provided more than satisfactory evidence of coherence, internal consistency, reliability, and validity (see ${ }^{19}$ ). Higher item-scores are indicative of a higher amount of experienced problems with self-directed executive actions.

* Dysexecutive questionnaire (DEX), part of the Behavioural Assessment of the Dysexecutive Syndrome (BADS). The DEX is a selfand other-rating questionnaire consisting of 20 items. Each item has a five-point Likert response style scale, ranging from 0 (never) to 4 (very often). It includes cognitive, affective and behavioral aspects of executive functioning (and thereby, self-regulation). Reliability and validity are satisfactory ${ }^{24}$. Higher item-scores are indicative of a higher amount of experienced problems with executive functioning. Total scores and scale scores were used to assess concurrent validity of the BDEFS.

* Barratt Impulsiveness Scale-Eleventh edition, Dutch version (BIS-11), The Barratt Impulsiveness Scale (BIS-11) is a 30 -item questionnaire, measuring aspects of impulsivity, with sufficient reliability and validity ${ }^{25,26}$. It has the same four-point Likert response style scale as the BDEFS. The original, English language version consists of three factor subscales: attention-impulsivity, motorimpulsivity and non-planning impulsivity. Higher item-scores are indicative of a higher amount of impulsivity (some items being reverse-scored). Total scores and scale scores were used in order to assess concurrent validity of the BDEFS, particularly its self-restraint subscale. The Brazilian-Portuguese translation and adaptation of the BIS- $11^{27}$ revealed a different factor structure than the original version. Two main factors were derived and form the scales: inhibitory control and non-planning impulsiveness, including other items than the original English non-planning scale. These differing BIS-11 scales were also taken into account within the present study because the Brazilian-Portuguese BDEFS translation and adaptation study ${ }^{23}$ served as an example, and used the BIS-11 as well to assess concurrent validity.

\section{Procedure}

The ISPOR translation and cultural adaptation "Principles of Good Practice" were closely adhered to during the BDEFS translation and adaptation process 22 . These principles involve the following major steps: 1) preparation (plan design and gain permission from Barkley, the BDEFS developer); 2) forward translations (two translations into Dutch); 3) reconciliation (comparison and consensus session concerning forward translations); 4) back translation (translation back into English by a bilingual native English and Dutch speaker); 5) back translation review (comparison of original and backtranslated versions and consensus session); 6) harmonization (result of consensus session) 7) cognitive debriefing (translated BDEFS test in small sample of 8 persons with oral evaluation of items and further remarks); 8) review of cognitive debriefing results and finalization (consensus session concerning final translation after last subtle changes); 9) proofreading (final control for errors); 10) final report. These steps also correspond with the guidelines provided by Beaton et al. concerning the process of cross-cultural adaptation of self-report measures ${ }^{28}$. Furthermore, an earlier BDEFS translation in Brazilian
Portuguese ${ }^{23}$ served as a successful translation and adaptation example. After the "Principles of Good Practice" steps, 25 bilingual Dutch adults filled in both the Dutch and English BDEFS 89-item versions with a few days in between. Lastly, the Dutch BDEFS version and the DEX and BIS11 questionnaires were administered to 60 healthy Dutch adults in order to measure concurrent validity (same procedure followed $\mathrm{as}^{23}$. In case of missing values on questionnaires, participants were contacted to fill in those items; therefore, no missing values remained.

\section{Data analysis}

For analyses aiming to measure the semantic equivalence of the Dutch BDEFS translation, answers on both the Dutch and English BDEFS, as completed by 25 bilingual Dutch adults, were compared, and Spearman correlations were derived (item responses of questionnaires not normally distributed). Furthermore, as in the earlier successful translation of the BDEFS in Brazilian Portuguese, a Bland Altman plot was made for analysis of agreement between the two versions and to search for a proportional bias in the data (for more information concerning this analysis technique, see $\left.{ }^{23}\right)$. Next, Cronbach's alpha coefficients were determined in order to analyse the internal consistency/reliability between items. Lastly, with the data of 60 healthy Dutch adults who filled in the Dutch BDEFS and DEX and BIS-11, concurrent validity analyses were performed.

\section{Results}

* Semantic equivalence. The original and translated BDEFS data of 25 bilingual Dutch adults were compared to assess semantic equivalence. All items and (sub) scales were taken into account (see Table 1 for all item and scale Spearman's rho scores). Spearman's rho of total scores was high: $.84(\mathrm{p}=.01)$. Furthermore, all five subscales showed high correlations; Spearman's rho was .89 for Self-management to time, .84 for Self-organization, .82 for Self-restraint, .91 for Self-motivation, and .86 for Self-regulation of emotion. Of the 89 items, 82 showed significant and moderate-to-high correlations. Twenty-eight items showed high correlations $(.70<r h o)$ and fifty-three items showed moderate correlations $(.30<r h o<.70)$. For item number 73 , "Unable to work as well as others without supervision or frequent instruction", Spearman's rho could not be calculated because all participants (having higher/university degree levels of education) gave the same answer "Never or seldom", which caused a variance of 0 and lack of standard deviation. All of the above indicates good correspondence between the original and translated BDEFS versions.

${ }^{*}$ Internal consistency/reliability. As in previous studies ${ }^{19,23}$, internal consistency of the Dutch BDEFS version was measured by computing Cronbach's alpha for the five subscales and the total score. This resulted in the following findings: Cronbach's alpha for the total score was .94, for Self-management to time it was .86, and for Self-organization, Self-restraint, Self-motivation and Selfregulation of emotion Cronbach's alpha's were $.92, .81, .75$ and .90, respectively. Thus, the Dutch BDEFS translation showed high values for internal consistency, which is comparable to values of the original questionnaire (for those results, see ${ }^{19}$ ).

${ }^{*}$ Total score difference between Dutch and English BDEFS versions and regression analysis. The mean difference of 4.76 (Standard deviation 8.25) that was found between the total scores of the two BDEFS versions was significant (Mean total score Dutch version $=127.00$, SD 15.20; Mean total score English version $=122.24 ; \mathrm{SD}$ $14.18 ; p=.01)$. However, the regression analysis, undertaken in a search for the presence of a proportional bias in the mean data, did not yield a significant result (unstandardized coefficient mean 0.08; standard error .12; standardized coefficient .13; t score .63; $p=.54$ ), indicating no proportional bias in the data. Consequently, a Bland Altman plot was constructed, showing that all but two Dutch-English BDEFS total scores fell within the $95 \%$ confidence range, indicating moderate clinical agreement between the questionnaires. 
Table 1. Spearman's rho for BDEFS items and (sub) scales

Item

1 Procrastinate or put off doing things until the last minute

2 Poor sense of time

3 Waste or mismanage my time

4 Not prepared on time for work or assigned tasks

5 Fail to meet deadlines for assignments

6 Have trouble planning ahead or preparing for upcoming events

7 Forget to do things I am supposed to do

8 Can't seem to accomplish the goals I set for myself

9 Late for work or scheduled appointments

10 Can't seem to hold in mind things I need to remember to do

11 Can't seem to get things done unless there is an immediate deadline

12 Have difficulty judging how much time it will take to do something or get somewhere

13 Have trouble motivating myself to start work

14 Have difficulty motivating myself to stick with my work and get it done

15 Not motivated to prepare in advance for things I know I am supposed to do

16 Have trouble completing one activity before starting into a new one

17 Have trouble doing what I tell myself to do

18 Difficulties following through on promises or commitments I may make to others

19 Lack self-discipline

20 Have difficulty arranging or doing my work by its priority of importance; can't "prioritize" well

21 Find it hard to get started or get going on things I need to get done

22 I do not seem to anticipate the future as much or as well as others

23 Can't seem to remember what I previously heard or read about

24 I have trouble organizing my thoughts

25 When I am shown something complicated to do, I cannot keep the information in mind so as to imitate or do it correctly

26 I have trouble considering various options for doing things and weighing their consequences

27 Have difficulties saying what I want to say

28 Unable to come up with or invent as many solutions to problems as others

29 Find myself at a loss for words when I want to explain something to others

30 Have trouble putting my thoughts down in writing as well or as quickly as others

31 Feel I am not as creative or inventive as others of my level of intelligence

32 In trying to accomplish goals or assignments, I find I am not able to think of as many ways of doing things as others

33 Have trouble learning new or complex activities as well as others

34 Have difficulty explaining things in their proper order or sequence

35 Can't seem to get to the point of my explanations as quickly as others

36 Have trouble doing things in their proper order or sequence

37 Unable to " think on my feet" or respond as effectively as others to unexpected events

38 I am slower than others at solving problems I encounter in my daily life

39 Easily distracted by irrelevant events or thoughts when I must concentrate on something

40 Not able to comprehend what I read as well as I should be able to do; have to reread material to get its meaning

41 Cannot focus my attention on tasks or work as well as others

42 Easily confused

43 Can't seem to sustain my concentration on reading, paperwork, lectures, or work

44 Find it hard to focus on what is important from what is not important when I do things

$45 \mathrm{I}$ don't seem to process information as quickly or as accurately as others

46 Find it difficult to tolerate waiting; impatient

47 Make decisions impulsively

48 Unable to inhibit my reactions or responses to events or others

49 Have difficulty stopping my activities or behavior when I should do so

50 Have difficulty changing my behavior when I am given feedback about my mistakes

51 Make impulsive comments to others

52 Likely to do things without considering the consequences for doing them

53 Change my plans at the last minute on a whim or last minute impulse

54 Fail to consider past relevant events or past personal experiences before responding to situations (I act without thinking)

55 Not aware of things I say or do

Rho $\quad \mathrm{P}$

\begin{tabular}{l|l}
$.72^{* *}$ & $<.01$
\end{tabular}

$49^{* *}$

$.79 * *$

.21

$.58^{* *}$

$.41^{*}$

$.41^{*}$

$.66^{* *}$

$.79^{* *}$

$.60^{* *}$

$.81^{* *}$

$.65^{* *}$

$.83^{* *}$

$.54^{* *}$

$.70^{* *}$

$.74^{* *}$

$.69 *$

$.35^{*}$

$.65^{* *}$

$.45^{*}$

$.50 * *$

$-.13$

$.68^{* *}$

$.36^{*}$

$.58^{* *}$

$.42^{*}$

$.90^{* *}$

$.60^{* *}$

$.68^{* *}$

$.40^{*}$

$.66^{* *}$

.18

$.66^{* *}$

$.56^{* *}$

$.66^{* *}$

$.41^{*}$

$.56^{* *}$

$.34^{*}$

$.88^{* *}$

$.76^{* *}$

$.56^{* *}$

.27

$.85^{* *}$

$69^{* *}$

.33

.89 **

$.86^{* *}$

$53^{* *}$

$.58^{* *}$

$.68^{* *}$

$.86^{* *}$

$.69^{* *}$

$.57^{* *}$

$.66^{* *}$

.27
.01

$<.01$

.16

$<.01$

.02

.02

$<.01$

$<.01$

$<.01$

$<.01$

$<.01$

$<.01$

$<.01$

$<.01$

$<.01$

$<.01$

.05

$<.01$

.01

$<.01$

.27

$<.01$

.04

$<.01$

.02

$<.01$

$<.01$

$<.01$

.02

$<.01$

.20

$<.01$

$<.01$

$<.01$

.02

$<.01$

.05

$<.01$

$<.01$

$<.01$

.10

$<.01$

$<.01$

.06

$<.01$

$<.01$

$<.01$

$<.01$

$<.01$

$<.01$

$<.01$

$<.01$

$<.01$ 


\begin{tabular}{|c|c|c|}
\hline Item & Rho & $\mathrm{P}$ \\
\hline 56 Have difficulty being objective about things that affect me & $.46^{*}$ & .01 \\
\hline 57 Find it hard to take other people's perspectives about a problem or situation & $.56^{* *}$ & $<.01$ \\
\hline 58 Don't think about or talk things over with myself before doing something & $.41^{*}$ & .02 \\
\hline 59 Trouble following the rules in a situation & $.71^{* *}$ & $<.01$ \\
\hline 60 More likely to drive a motor vehicle much faster than others (Excessive speeding) & $.83^{* *}$ & $<.01$ \\
\hline 61 Have a low tolerance for frustrating situations & $.85^{* *}$ & $<.01$ \\
\hline 62 Cannot inhibit my emotions as well as others & $.51^{* *}$ & .01 \\
\hline 63 I don't look ahead and think about what the future outcomes will be before I do something (I don't use my foresight) & $.36^{*}$ & .04 \\
\hline 64 I engage in risk taking activities more than others are likely to do & $.78^{* *}$ & $<.01$ \\
\hline 65 Likely to take short cuts in my work and not do all that I am supposed to do & $.52^{* *}$ & $<.01$ \\
\hline 66 Likely to skip out on work early if my work is boring to do & $.52^{* *}$ & $<.01$ \\
\hline 67 Do not put as much effort into my work as I should or than others are able to do & $.75^{* *}$ & $<.01$ \\
\hline 68 0thers tell me I am lazy or unmotivated & $1.00^{* *}$ & $<.01$ \\
\hline 69 Have to depend on others to help me get my work done & $.85^{* *}$ & $<.01$ \\
\hline 70 Things must have an immediate payoff for me or I do not seem to get them done & $.63^{* *}$ & $<.01$ \\
\hline 71 Have difficulty resisting the urge to do something fun or more interesting when I am supposed to be working & $.93^{* *}$ & $<.01$ \\
\hline 72 Inconsistent in the quality or quantity of my work performance & $.80^{* *}$ & $<.01$ \\
\hline 73 Unable to work as well as others without supervision or frequent instruction & *** & *** \\
\hline 74 I do not have the willpower or determination that others seem to have & $.70^{* *}$ & $<.01$ \\
\hline 75 I am not able to work toward longer term or delayed rewards as well as others & -.08 & .36 \\
\hline 76 I cannot resist doing things that produce immediate rewards even if they are not good for me in the long run & $.41^{*}$ & .02 \\
\hline 77 Quick to get angry or become upset & $.86^{* *}$ & $<.01$ \\
\hline 78 Overreact emotionally & $.84^{* *}$ & $<.01$ \\
\hline 79 Easily excitable & $.34^{*}$ & .05 \\
\hline 80 Unable to inhibit showing strong negative or positive emotions & $.60^{* *}$ & $<.01$ \\
\hline 81 Have trouble calming myself down once I am emotionally upset & $.40^{*}$ & .02 \\
\hline 82 Cannot seem to regain emotional control and become more reasonable once I am emotional & $.42^{*}$ & .02 \\
\hline $\begin{array}{l}83 \text { Cannot seem to distract myself away from whatever is upsetting me emotionally to help calm me down. I can't refocus my mind to a } \\
\text { more positive framework }\end{array}$ & $.63^{* *}$ & $<.01$ \\
\hline 84 Unable to manage my emotions in order to accomplish my goals successfully or get along well with others & $.38^{*}$ & .03 \\
\hline 85 I remain emotional or upset longer than others & $.82^{* *}$ & $<.01$ \\
\hline $\begin{array}{l}86 \text { I find it difficult to walk away from emotionally upsetting encounters with others or leave situations in which I have become very } \\
\text { emotional }\end{array}$ & $.78^{* *}$ & $<.01$ \\
\hline 87 I cannot rechannel or redirect my emotions into more positive ways or outlets when I get upset & $.72^{* *}$ & $<.01$ \\
\hline 88 I am not able to evaluate an emotionally upsetting event more objectively & $.69^{* *}$ & $<.01$ \\
\hline 89 I cannot redefine negative events into more positive viewpoints when I feel strong emotions & $.74^{* *}$ & $<.01$ \\
\hline EF Count Symptoms & $.85^{* *}$ & $<.01$ \\
\hline ADHD Index & $.68^{* *}$ & $<.01$ \\
\hline Self-management to time & $.89^{* *}$ & $<.01$ \\
\hline Self-organization & $.84^{* *}$ & $<.01$ \\
\hline Self-restraint & $.82^{* *}$ & $<.01$ \\
\hline Self-motivation & $.91^{* *}$ & $<.01$ \\
\hline Self-regulation of emotion & $.86^{* *}$ & $<.01$ \\
\hline Total Score & $.84^{* *}$ & $<.01$ \\
\hline
\end{tabular}

* Significant at $p=.05$ level. ${ }^{* *}$ Significant at $p=.01$ level. ${ }^{* * *}$ Not applicable.

* Concurrent validity, measured by comparisons between BDEFS, $D E X$ and BIS-11. Lastly, as for concurrent validity, correlations between BDEFS, DEX and BIS-11 total scores were significant, with high $($ rho $=.72)$ and moderate $($ rho $=.43)$ values, respectively (see Table 2). The correlation between the BDEFS total score and the (Brazilian-Portuguese ${ }^{27}$ ) BIS-11 inhibitory control scale was significant (rho $=.55$ ) whereas the correlation with the Brazilian BIS-11 non-planning impulsiveness scale was insignificant (rho = -.09). The correlations between the BDEFS self-restraint scale and DEX behavior and BIS-11 total scores were also significant with moderate correlations (rho's of .52 and .51). The correlation between the BDEFS self-restraint scale and Brazilian BIS-11 inhibitory control scale was significant (rho $=.53$ ).

In summary: semantic equivalence was high (rho total scores $=.84$ ), construct validity analyses revealed moderate to high item correlations, no proportional bias was present, the translation showed high internal consistency (Cronbach's alpha $=.94$ ) and concurrent validity was high to moderate for the BDEFS translation as compared to the DEX and BIS-11 (rho $=.72$ and $r h o=.43)$. 
Table 2. Spearman's rho for Dutch BDEFS, DEX and BIS-11 questionnaires

\begin{tabular}{|c|c|c|c|c|c|c|c|c|c|c|c|}
\hline & Dex total & $\begin{array}{c}\text { Dex } \\
\text { emotion }\end{array}$ & $\begin{array}{c}\text { Dex } \\
\text { cognitive }\end{array}$ & $\begin{array}{c}\text { Dex } \\
\text { behavior }\end{array}$ & Bis-11 total & $\begin{array}{l}\text { Bis-11 } \\
\text { impuls. }\end{array}$ & $\begin{array}{l}\text { Bis-11 } \\
\text { motor- } \\
\text { impuls. }\end{array}$ & $\begin{array}{l}\text { Bis-11 non- } \\
\text { plan }\end{array}$ & $\begin{array}{l}\text { Bis-11 } \\
\text { attention } \\
\text { impuls. }\end{array}$ & $\begin{array}{c}\text { Bis-11 } \\
\text { inhibitory } \\
\text { control } \\
\text { Portuguese }\end{array}$ & $\begin{array}{l}\text { Bis-11 non } \\
\text { planning } \\
\text { Portuguese }\end{array}$ \\
\hline BDEFS Total score & $.72^{* *}$ & $.47^{* *}$ & $.60^{* *}$ & $.58^{* *}$ & $.43^{* *}$ & $.41^{* *}$ & .07 & $.30^{*}$ & $.54^{* *}$ & $.55^{* *}$ & -.09 \\
\hline $\begin{array}{l}\text { BDEFS Self- } \\
\text { management of } \\
\text { time }\end{array}$ & $.62^{* *}$ & $.53^{* *}$ & $.48^{* *}$ & $.36 * *$ & $.32^{*}$ & $.29 *$ & .12 & .24 & $.33^{*}$ & $.36^{* *}$ & .12 \\
\hline $\begin{array}{l}\text { BDEFS self- } \\
\text { organization }\end{array}$ & $.56^{* *}$ & $.38^{* *}$ & $.52^{* *}$ & $.41^{* *}$ & $34^{* *}$ & $.27^{*}$ & -.11 & $.32^{*}$ & $.48^{* *}$ & $.41^{* *}$ & -.16 \\
\hline $\begin{array}{l}\text { BDEFS self- } \\
\text { restraint }\end{array}$ & $.43^{* *}$ & .14 & .23 & $.52^{* *}$ & $.51^{* *}$ & $.50^{* *}$ & $.36^{* *}$ & $.28^{*}$ & $.41^{* *}$ & $.53^{* *}$ & .10 \\
\hline $\begin{array}{l}\text { BDEFS self- } \\
\text { motivation }\end{array}$ & $.56^{* *}$ & $.41^{* *}$ & $.40^{* *}$ & $.48^{* *}$ & $34^{* *}$ & $.40^{* *}$ & .16 & .12 & $.45^{* *}$ & $.44^{* *}$ & .10 \\
\hline $\begin{array}{l}\text { BDEFS self- } \\
\text { regulation of } \\
\text { emotion }\end{array}$ & $.33^{*}$ & .14 & $.31^{*}$ & $.40^{* *}$ & -.05 & .04 & -.15 & -.06 & .18 & .16 & $-.39 * *$ \\
\hline $\begin{array}{l}\text { BDEFS EF Count } \\
\text { symptoms }\end{array}$ & $.55^{* *}$ & $.43^{* *}$ & $.54^{* *}$ & $.39 * *$ & $.37^{* *}$ & $.39 * *$ & .03 & .20 & $.57^{* *}$ & $.50^{* *}$ & -.11 \\
\hline $\begin{array}{l}\text { BDEFS ADHD } \\
\text { Index }\end{array}$ & $.55^{* *}$ & $.39 * *$ & $.48^{* *}$ & $.38^{* *}$ & $.40^{* *}$ & $.39 * *$ & .13 & $.26^{*}$ & $.51^{* *}$ & $.49^{* *}$ & .09 \\
\hline
\end{tabular}

${ }^{*}$ Correlation significant at $p=.01$ level. ${ }^{*}$ Correlation significant at $p=.05$ level.

\section{Discussion}

As outlined, and in the light of earlier stated hypotheses, this BDEFS translational process points to successful findings in terms of construct validity, similarity, reliability and concurrent validity. That is, it showed high semantic equivalence, high internal consistency, moderate to high item-correlations and no proportional bias.

Compared to several other studies, internal consistency findings of the BDEFS translation were in line with psychometric data of the original version and other-language translations ${ }^{19,23}$. Furthermore, semantic equivalence findings for the translation were comparable to those of the Brazilian-Portuguese versus original BDEFS 23 . Concerning the concurrent validity analyses, it seems logical that the BDEFS total score and DEX total score comparisons revealed higher correlations than the BDEFS total score and BIS11 total score. That is, both the BDEFS and DEX predominantly aim to measure executive function in a broad spectrum of components, whereas the BIS-11 primarily aims to measure impulsivity. Impulsivity as a concept is related to executive function as well, however, it touches only one component of it.

Furthermore, a closer look at the Brazilian and English BIS-11 versions revealed differences in factor structures as outlined earlier; the Brazilian Portuguese containing the factors of "inhibitory control" and "non-planning impulsiveness". The latter factor can, on a non-pathological side, be described as being "now-orientated", letting things happen instead of looking to the future and planning ahead or controlling everything. On a more pathological side, non-planning impulsiveness could take the form of not controlling oneself/planning things at all in life, not striving for keeping a job, and spending money without preserving something for one's future. As reported, the Dutch BDEFS total and self-restraint scores correlated positively with the Brazilian BIS-11 inhibitory control factor. Contrarily, the BDEFS total score was not correlated to the Brazilian BIS-11 non-planning impulsiveness scale score. Item content of the BDEFS, DEX and BIS-11 inhibitory control scales may primarily exist of various pathological executive function symptoms, like problems with self-restraint. In contrast, BIS-11's non-planning impulsiveness items show more nuance in the sense of both a non-pathological and a pathological side to it, differing per person and related to executive function. In other words, not every questionnaire item within the BIS-11 points to impairment in executive functioning; an attitude of "living in the here and now" and letting things happen like they come, may be more of a personally different, non-pathological style and preference, as long as it does reach extreme forms/amounts.

This could fit one of the other findings in this study (Table 2), which shows that the BDEFS "problems in self-regulation of emotions" scale is negatively correlated to the Brazilian BIS-11 non-planning impulsiveness scale score. This finding means that if one does not tend to plan things ahead and takes things more like they come (higher score on non-planning impulsiveness), one experiences fewer problems in calming oneself after a (regularly less "planned") emotional moment has taken place (low score on self-regulation of emotion problems). In other words, one may in fact not be triggered by emotional events in a pathological sense. But, to the contrary, when one tends to plan everything ahead, one could more easily get into a panic while thinking "Oh no, I did not plan for this, what is happening to me, I am getting overwhelmed by this".

This brings us to the point that it is of distinct importance to carefully define and outline, based on a theoretical framework, what one does and does not interpret as "pathology/symptomatology" versus "non-pathological personal differences in executive functioning". Barkley earlier described how diverse visions and operational accents concerning executive functioning differed throughout the years ${ }^{13}$. The pitfall could be to put certain behavior and/or assessment instruments too quickly under, or out of, an umbrella paradigm like executive actions, and/or interpret behavior as pathological instead of keeping eye for its distinct characteristics and potential non-pathological aspects.

Despite the earlier mentioned positive key findings of this study, a few limitations should be noted. Most, but not all items (94\%) showed moderate-to-high correlations between the original English language BDEFS version and the Dutch translation, when assessed in 25 bilingual Dutch adults. Furthermore, the means of the total scores differed significantly between the versions. Because of this difference, the Bland Altman plot did not show a perfect picture concerning the amount of clinical agreement between the questionnaires. That is, $92 \%$ of participant scores, instead of the $95 \%$ that is typically sought, fall within the area that points to good clinical agreement. Nevertheless, the direction of these findings did not show a significant proportional bias in the regression analysis. It is quite likely that cultural linguistic differences provide an explanation for 
these differences: although one may fluently speak a language like English, one's native language may lead to a higher identification with and recognition of symptoms as described in questionnaire items. One item (73), "Unable to work as well as others without supervision or frequent instruction" showed no variation in scores (all answers "never or seldom"). And so as a consequence, Spearman's rho could not be calculated. However, this item is not considered as "useless/unremarkable". That is, it is logically imaginable that the 25 bilingual adults, all having higher degree education histories, usually work as well as others without supervision or frequent instruction. Furthermore, no factor analysis could be performed, because of a small sample size (60) and because not all items showed high correlations ${ }^{29}$. Further research on large samples examining the factor structure of the Dutch BDEFS is required to compare it with the available factor analysis of the original BDEFS ${ }^{19}$.

Lastly, future research should test the applicability of the Dutch BDEFS in clinical populations by conducting clinical practice studies in mental health care institutions, administering it to patients suffering from several psychiatric disorders. Findings from such studies will then hopefully facilitate and promote the use of the BDEFS in Dutch clinical practice. In several countries, the BDEFS is already used in diagnostic and intervention studies, mostly in patient groups with ADHD, but also in studies assessing neurocognitive ability tasks in combination with the BDEFS or for other research questions involving executive function/self-regulation ${ }^{30-33}$. Hopefully, this Dutch BDEFS translation and adaptation may become the prelude for this kind of studies and BDEFS applications in Dutch speaking countries. When combined with neuropsychological ability measures and (self-report) instruments assessing one's personal styles (aspects like impulsivity) and quality of life aspects, the use of the BDEFS can also contribute to integrated and tailor made diagnostic profiles and treatment indications. That is, we believe the ideal key lays in the integration of both perspectives. Thereby, the availability of the BDEFS in Dutch clinical practice may improve the clinician's toolbox.

\section{Conflicts of interest statement}

The authors declare that the research was conducted in the absence of any commercial or financial relationships that could be construed as a potential conflict of interest.

\section{Disclosure}

Prof. Barkley receives royalties from Guilford Publications for the English version of the BDEFS Scale.

\section{Acknowledgments}

The authors would like to express their thanks to Mrs. Wendy Prime, MSc, and Mrs. Nathalie Fiandaca, MSc, for their roles in the translational process.

\section{References}

1. Craig F, Margari F, Legrottaglie AR, Palumbi R, de Giambattista C, Margari L. A review of executive function deficits in autism spectrum disorder and attention-deficit/hyperactivity disorder. Neuropsychiatr Dis Treat. 2016;12:1191-202.

2. Duijkers JC, Vissers CT, Egger JI. Unraveling executive functioning in dual diagnosis. Front Psychol. 2016;7:979.

3. Egger JIM, De Mey HRA, Janssen GTL. Assessment of executive functioning in psychiatric disorders: functional diagnosis as the overture of treatment. Clin Neuropsychiatry. 2007;4 (3):111-6.

4. Goschke T. Dysfunctions of decision-making and cognitive control as transdiagnostic mechanisms of mental disorders: advances, gaps, and needs in current research. Int J Methods Psychiatr Res. 2014;23 Suppl 1:41-57.

5. Hill EL. Executive dysfunction in autism. Trends Cogn Sci. 2004;8(1): 26-32.

6. Janssen GTL. Diagnostic assessment of psychiatric patients: a contextual perspective on executive functioning (dissertation). Nijmegen: Donders series; 2013
7. Pennington BF, Ozonoff S. Executive functions and developmental psychopathology. J Child Psychol Psychiatry. 1996;37(1):51-87.

8. Snyder HR, Miyake A, Hankin BL. Advancing understanding of executive function impairments and psychopathology: bridging the gap between clinical and cognitive approaches. Front Psychol. 2015;6:328.

9. Vissers C, Koolen S, Hermans D, Scheper A, Knoors H. Executive functioning in preschoolers with specific language impairment. Front Psychol. 2015;6:1574.

10. Wiers RW, Cousijn J, ter Mors-Schulte M, den Uijl T, Goudriaan A, Schilt T, et al. State of the art: neurocognitieve effecten van verslaving. ZonMW; 2012.

11. Barkley RA. Behavioral inhibition, sustained attention, and executive functions: constructing a unifying theory of ADHD. Psychol Bull. 1997;121(1):65-94.

12. Toplak ME, West RF, Stanovich KE. Practitioner review: do performancebased measures and ratings of executive function assess the same construct? J Child Psychol Psychiatry. 2013;54(2):131-43.

13. Barkley RA. Executive functions: What they are, how they work, and why they evolved. New York: The Guilford Press; 2012.

14. Barkley RA, Murphy KR. The Nature of Executive Function (EF) Deficits in Daily Life Activities in Adults with ADHD and Their Relationship to Performance on EF Tests. J Psychopathol Behav Assess. 2011;33(2);137-58.

15. Vélez-Pastrana MC, González RA, Rodríguez Cardona J, Purcell Baerga P, Alicea Rodríguez Á, Levin FR. Psychometric properties of the Barkley deficits in executive functioning scale: A Spanish-language version in a community sample of Puerto Rican adults. Psychol Assess. 2016;28(5):483-98.

16. Lezak MD. Neuropsychological assessment. 4th ed. New York: Oxford University Press; 2004.

17. Barkley RA, Fischer M. Predicting impairment in major life activities and occupational functioning in hyperactive children as adults: self-reported executive function (EF) deficits versus EF tests. Dev Neuropsychol. 2011;36(2):137-61.

18. Barkley RA, Murphy KR. Impairment in occupational functioning and adult ADHD: the predictive utility of executive function (EF) ratings versus EF tests. Arch Clin Neuropsychol. 2010;25(3):157-73.

19. Barkley RA. Barkley Deficits in Executive Functioning Scale (BDEFS). New York: The Guilford Press; 2011.

20. Miyake A, Friedman NP, Emerson MJ, Witzki AH, Howerter A, Wager TD. The unity and diversity of executive functions and their contributions to complex "frontal lobe" tasks: a latent variable analysis. Cogn Psychol. 2000;41(1):49-100.

21. Barkley RA. Barkley Deficits in Executive Functioning Scale - Children and Adolescents (BDEFS-CA). New York: Guilford Press; 2012.

22. Wild D, Grove A, Martin M, Eremenco S, McElroy S, Verjee-Lorenz A, et al.; ISPOR Task Force for Translation and Cultural Adaptation. Principles of good practice for the translation and cultural adaptation process for patient-reported outcomes (PRO) measures: report of the ISPOR task force for translation and cultural adaptation. Value Health. 2005;8(2):94-104.

23. Godoy VP, Mata FG, Conde BR, Oliveira e Souza CA, Martins ALG, Mattos P, et al. Brazilian Portuguese transcultural adaptation of Barkley Deficits in Executive Functioning Scale (BDEFS). Arch Clin Psychiatry. 2015;42(6):147-52.

24. Wilson BA, Alderman N, Burgess PW, Emslie H, Evans JJ. Behavioural assessment of the dysexecutive syndrome. St Edmunds, UK: Thames Valley Test Company; 1996.

25. Patton JH, Stanford MS, Barratt ES. Factor structure of the Barratt Impulsiveness Scale. J Clin Psychol. 1995;51(6):768-74.

26. Stanford MS, Mathias CW, Dougherty DM, Lake SL, Anderson NE, Patton JH. Fifty years of the Barratt Impulsiveness Scale: an update and review. Personality and Individual Differences. 2009;47:385-95.

27. Malloy-Dinez LF, Mattos P, Leite WB, Abreu N, Coutinho G, de Paula JJ, et al. Translation and cultural adaptation of Barratt Impulsiveness Scale (BIS-11) for administration in Brazilian adults. J Bras Psiquiatr. 2010;59(2):99-105.

28. Beaton DE, Bombardier C, Guillemin F, Ferraz MB. Guidelines for the process of cross-cultural adaptation of self-report measures. Spine (Phila Pa 1976). 2000;25(24):3186-91.

29. Field A. Discovering statistics using IBM SPSS. London, England: SAGE Publications Ltd; 2017.

30. Kamradt JM, Ullsperger JM, Nikolas MA. Executive function assessment and adult Attention-Deficit/Hyperactivity Disorder: tasks versus ratings 
on the Barkley Deficits in Executive Functioning Scale. Psychol Assess. 2014;26(4):1095-105.

31. Vergara-Moragues E, González-Saiz F, Lozano Rojas O, Bilbao Acedos I, Fernández Calderón F, Betanzos Espinosa P, et al. Diagnosing adult Attention Deficit/Hyperactivity Disorder in patients with cocaine dependence: discriminant validity of Barkley Executive dysfunction symptoms. Eur Addict Res. 2011;17(6):279-84
32. Vlagsma TT, Koerts J, Tucha O, Dijkstra HT, Duits AA, van Laar T, et al. Objective versus subjective measures of executive functions: predictors of participation and quality of life in Parkinson disease? Arch Phys Med Rehabil. 2017;98(11):2181-7.

33. Ferreira BP, Malloy-Diniz LF, Parma JO, Nogueira NGHM, ApolinárioSouza T, Ugrinowitsch H, et al. Self-controlled feedback and learner impulsivity in sequential motor learning. Percept Mot Skills. 2019;126(1):157-79. 